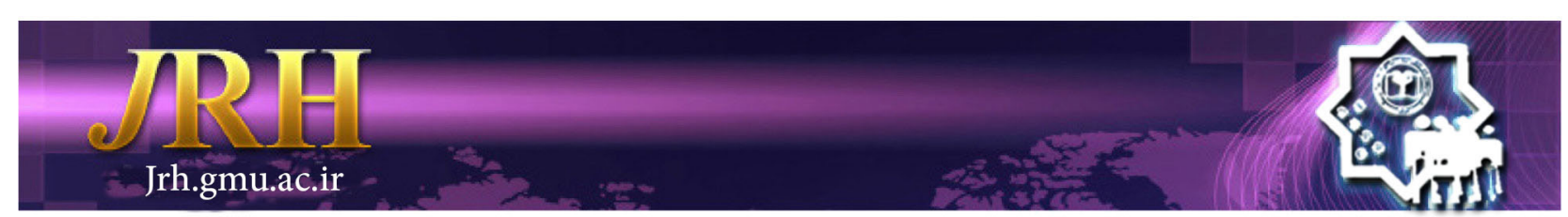

\title{
Analysis of the relationship between health-related quality of life and social capital of rural people: an evidence from Iran
}

Zeinab Sharifi $^{1}$, Mehdi Nooripoor ${ }^{1}$

\section{Journal of Research \& Health \\ Social Development \& Health Promotion Research Center \\ Vol. 9, No.4, Jul \& Agu 2019 \\ Pages: $347-354$ \\ DOI: 10.29252 /jrh.9.4.347 \\ Original Article}

1. Department of Rural Development Management, Faculty of Agriculture, Yasouj University, Yasouj, Iran

Correspondence to: Mehdi Nooripoor, Department of Rural Development Management, Faculty of Agriculture,Yasouj University, Yasouj, Iran

Email: mnooripoor@yu.ac.ir

Received: 21 Oct 2016

Accepted: 25 Oct 2017

How to cite this article: Sharifi Z, Nooripoor M. Analysis of the relationship between health-related quality of life and social capital of rural people. J Research \& Health2019; 9(4): 347- 354

\begin{abstract}
Having a healthy lifestyle is a prerequisite for achieving sustainable development. Moreover, social capital is one of the important variables affecting the health of individuals in society. Thus, the purpose of this study was to investigate the relationship between social capital and health-related quality of life among rural people in Dena region located in southwest of Iran. 300 households were selected using multistage cluster sampling method. For data collection, SF-36 standard questionnaire was used to measure health-related quality of life. A research made questionnaire was also applied in order to examine social capital which its validity and reliability were confirmed. The correlation coefficients between both physical health and mental health and 5 dimensions of social capital was positive. Furthermore, the correlation between mental health and social trust and social networks was significant; moreover, the correlation coefficient between mental health and social cohesion was significant. However, the correlation between mental health and social norm and social participation was not significant. Considering a relationship between mental health and social trust as well as social networks and social cohesion, enhancement of the above dimensions should be taken into account in order to improve mental health.
\end{abstract}

Keywords: Development, Health, Quality of life, Social capital

\section{Introduction}

The quality of life is defined by the World Health Organization as the individual's perception of his/her status and position in the life regarding the culture and value system in which they live as well as the relation with goals, expectations, standards and preferences in individual's life [1]. Due to importance of life quality, it is addressed in most of health related studies and is assigned a prominent role by health researchers [2].

Having a healthy lifestyle, productive, qualitative, and acceptable lifetime, and a life free of disease and disability is a public right and a prerequisite for achieving sustainable development that can be achieved through government policies. The main concern 
of health is preserving capitals (human, natural, social, and economic) in the direction of intergenerational justice. The villagers' health is one of the essential foundations of sustainable development that is considered in recent years and has attracted the attention of national and international organizations [3]. In fact, the role of health in the promotion of human development is undeniable. According to human development approach, human is the center of development and a healthy person can create a healthy society [4]. On the other hand, one of the important variables affecting the health of any society is the social capital and its derived dimensions [5]. According to John Field, the idea that social capital and health are linked together dates back at least to a century. Putnam also believes that social capital is associated with health [6]. Putnam argues that social capital creates link between members of different groups and plays an important role in providing information about external sources such as employment opportunities, promulgating innovation as well as promoting the idea of health. Network theorists believe that the existence of social networks as a buffer against internal stressors plays a positive role; that is, social netwoks have a very important and effective impact on people's self-esteem and can enhance the ability to cope with life problems and depression and ultimately can lead to feelings of mental health by providing emotional support, friendship, and opportunities for meaningful social action in the form of social capital [5]. In fact, the more social capital the society has, the higher level of health there is [2]. The potential impact of social capital on health has increased the number of studies in different disciplines such as sociology, economics, political science, and public health [7]. Koohi and Soltani Bahram [5], Mirsardo [8], Gilbert et al [9], and Fujisawa et al [10] have shown that the social capital variable has a significant positive correlation with the respondents' general health. Kim and Kawachi demonstrated that higher level of social capital is accompanied with fewer days with poor physical and mental health and restrictions on activities [11]. Although several studies have been conducted on the quality of life in rural areas, less research focuses on health-related quality of life. On the other hand, despite various studies on the relationship between health and social capital, few researchers have adderessed that relationship among the villagers. Therefore, this study aimed to investigate the health-related quality of life of rural people and its relationship with social capital.

\section{Method}

The statistical population of this study consisted 2500 heads of rural households in the central district of Dena county, Kohgiluyeh and Boyer-Ahmad province, Iran, 2015. Using Morgan table, a sample size of 300 households was determined and the participants were chosen through multi stage cluster sampling. The data were collected using a researcher made questionnaire with three sections on general information (gender, age, and educational level) and Short Form Health survey (SF-36 questionnaire) and questionnaire for measuring social capital.

The SF-36 questionnaire has already been translated into Persian and its validity and reliability were confirmed [12] and it is one of the most common questionnaires to assess health related quality of life for both healthy and unhealthy people. The questionnaire measures health related quality of life in eight domains in the form of 36 questions and also contains 10 questions about physical functioning, 4 questions about role limitations due to physical problems and three questions about role limitations due to emotional problems, two questions about pain and its impact on daily activities, 5 questions about people's perception of their general health, two questions about social functioning, four questions about the freshness and vitality, and 5 questions about mental health. Two summary compounds can be obtained by integrating these scales: a summary of physical health measure and a summary of mental health assessment. A summary of 
physical health measure includes physical functioning, physical pain, role limitations due to physical problems, and general health. A summary of mental health assessment contains social functioning, mental health, freshness and vitality, and role limitations due to emotional problems [13]. For scoring the questionnaire, scores of items in each domain were added up and converted to a scale ranging from $0 \%$ (lowest or the worst possible level of functioning) to $100 \%$ (highest or the best possible level of functioning). However, it needs to be mentioned that the questionnaire was validated and finalized with 32 items measuring health related quality of life.

Social capital was measured through a questionnaire containing 30 questions in five dimensions, including social trust (7 items), social networks (8 items), social cohesion (5 items), social norms (3 items), and social participation (7 items) using a three-point Likert scale (low, medium, high) which its validity was confirmed using comments of rural development experts and its reliability was confirmed by achieving Cronbach's alpha coefficient of 0.430 to 0.862 . Noticed ethics in this study included: A sense of responsibility in selecting research topics to be regional and based on people's need, privacy notice of the individuals and try not to search and ask the questions which participants do not tend to respond as well as try to contact and gather information with respect to language, culture and local dialect. SPSS-19 was used in order to analyze data and descriptive statistics (mean and standard deviation) and inferential statistics (Pearson correlation test) were applied to analyze data.

\section{Results}

Table 1 shows the demographic status of the participants. Since the statistical population consisted of rural household heads, $97 \%$ of the participants were male and only $3 \%$ were female. $29.2 \%$ of the participants were in the age group of $41-50$ years, and only $17.2 \%$ were 30 years or younger. Moreover, 27.1\% of the participants were in the age group of $31-40$ years and $26.5 \%$ aged 51 years and older. Concerning educational status, $36.1 \%$ of the participants had diploma, $30.7 \%$, $16.4 \%$, and $16.8 \%$ had elementary school, guidance school, and university education, respectively.

\begin{tabular}{llc}
\multicolumn{3}{l}{ Table 1 The demographic status of the respondents } \\
\hline Variables & Groups & Valid percent \\
\hline \multirow{2}{*}{ Gender } & Female & 3.0 \\
& Male & 97.0 \\
\hline \multirow{5}{*}{ Age group } & 30 years and younger & 17.2 \\
& $31-40$ & 27.1 \\
& $41-50$ & 29.2 \\
& 51 years and older & 26.5 \\
\hline \multirow{4}{*}{ Education } & Elementary school & 30.7 \\
level & Guidance school & 16.4 \\
& Diploma & 36.1 \\
& University education & 16.8 \\
\hline
\end{tabular}

Health domains, the mean scores, and standard deviation are shown in Table 2. Among the health domains, physical functioning had the highest mean score (66.54) and role limitations due to physical problems had the lowest mean score (52.86). Overall, mean score of summary measure of physical health and summary measure of mental health were
60.04 and 57.49 respectively indicating that physical health status of the participants was slightly higher than their mental health. Dimensions of social capital, the mean of scores, and standard deviation are shown in Table 3. Among the dimensions of social capital, social cohesion and social norm had the highest mean score (2.25); whereas, 
social network had the lowest mean score (1.88). Overall, the mean score of social capital was higher than the average (2.16) (2).

Table 2 Health domains, their mean and standard deviation

\begin{tabular}{lcc}
\hline Health domains & Mean & $\begin{array}{c}\text { Standard } \\
\text { deviation }\end{array}$ \\
\hline Physical functioning & 66.54 & 28.42 \\
$\begin{array}{l}\text { Role limitations due to physical } \\
\text { problems }\end{array}$ & 52.86 & 31.0 \\
Physical pain & 54.83 & 31.71 \\
General health & 56.58 & 21.44 \\
Freshness and vitality & 65.55 & 26.23 \\
Social functioning & 59.61 & 28.15 \\
Role limitations due to emotional & 55.10 & 33.31 \\
problems & 53.94 & 23.46 \\
Mental health & 60.04 & 21.56 \\
Summary measure of physical health & 57.49 & 21.37 \\
Summary assessment of mental health & 5 \\
\hline Mean scores range from 0 (lowest or worst possible level of functioning) to \\
100 (highest or best possible level of functioning)
\end{tabular}

Table 3 Dimensions of social capital, the mean scores and standard deviation

\begin{tabular}{lcc}
\hline Dimensions & Mean & Standard deviation \\
\hline Social trust & 2.23 & 0.43 \\
Social network & 1.88 & 0.37 \\
Social cohesion & 2.25 & 0.48 \\
Social norm & 2.25 & 0.56 \\
Social participation & 2.17 & 0.45 \\
Social capital & 2.16 & 0.31 \\
\hline \multicolumn{2}{l}{ Mean scores range from 1 (low) to 3 (high) }
\end{tabular}

The results of Pearson correlation coefficients between dimensions of social capital and health are shown in Table 4. The results illustrated that the correlation coefficients between physical health and 5 dimensions of social capital are positive indicating that changes in physical health and five dimensions of social capital were in the same direction. Moreover, the correlation between physical health and social capital was generally positive. In other words, changes in physical health and social capital were in the same direction. However, based on the significant level, the relationship between physical health and dimensions of social capital as well as social capital in general were not statistically significant.

Furthermore, the positive correlation between mental health and the five dimensions of social capital suggested that changes are in the same direction. In addition, the correlation between mental health and social trust and social network were significant $(p<0.05)$; moreover, the correlation coefficient between mental health and social cohesion was significant $(p<0.01)$. Therefore, it can be stated that there is a relationship between mental health and social trust, social networks and social cohesion according to $95 \%$ and $99 \%$ confidence intervals (CIs). However, the correlation coefficient between mental health and social norm and social participation were not statistically significant. Moreover, the correlation between mental health and social capital in general was significant at the $1 \%$ level. Therefore, it can be concluded that there is a relationship between mental health and social capital in general considering $99 \%$ confidence intervals (CIs). 
Table 4 Pearson correlation coefficients between dimensions of social capital and physical and mental health

\begin{tabular}{lcccc}
\hline & \multicolumn{2}{c}{ Physical health } & \multicolumn{2}{c}{ Mental health } \\
\cline { 2 - 5 } $\begin{array}{l}\text { Dimensions of } \\
\text { social capital }\end{array}$ & $\begin{array}{l}\text { Correlation } \\
\text { coefficient }\end{array}$ & p-value & $\begin{array}{c}\text { Correlation } \\
\text { coefficient }\end{array}$ & p-value \\
\hline Social trust & 0.019 & 0.742 & $0.127^{*}$ & 0.027 \\
Social network & 0.077 & 0.182 & $0.144^{*}$ & 0.012 \\
Social cohesion & 0.061 & 0.296 & $0.199^{* *}$ & 0.001 \\
Social norm & 0.012 & 0.834 & 0.100 & 0.083 \\
Social partiipation & 0.062 & 0.286 & 0.112 & 0.052 \\
Social capital & 0.083 & 0.215 & $0.221 * *$ & 0.001 \\
\hline * $<0.05, * * \mathrm{p}<0.01$ & & & &
\end{tabular}

\section{Discussion}

This study aimed to investigate health-related quality of life and its relationship with social capital among the villagers. The results indicated that most participants were male and aged between 41 and 50 years. The majority of participants had diploma. Among the five dimensions of social capital, social cohesion and social norm had the highest mean score; whereas, social network had the lowest mean score.

Overall, the mean score of social capital was higher than the average. Moreover, among the 8 health domains, physical functioning had the highest mean score, but role limitations due to physical problems had the lowest mean score. In total, the mean score of summary measure of physical and mental health indicated that physical health status of the participants was slightly higher than their mental health. In addition, the results showed that the correlation coefficients between physical health and 5 dimensions of social capital was positive unraveling that changes in physical health and five dimensions of social capital were in the same direction. In fact, the more the social capital, the more the physical health.

A previous study showed a positive and significant relationship between social capital and physical health [14] that is in line with the current investigation; however, the relationship was not statistically significant in the present study. This difference might be due to this fact that the aforementioned study [14] was carried out among teachers; whereas, the current study were done among villagers. The results of this study contrasted with Zahedi Asl and Farokhi [15] and Musalia [7] as these studies indicated a significant and strong relationship between social capital and physical health.

In addition, there was a positive relationship between mental health and five dimensions of social capital. Furthermore, there was a significant relationship between mental health and social trust, social networks and social cohesion.

The results of Sharepour et al, also demonstrated a significant relationship between social trust and mental health of citizens in Tehran [16]. Moreover, the findings of Haghighatian and Jafari showed a significant positive relationship between social trust, social cohesion and social norms and social capital in general and mental health [17]. The study of Hezar Jaribi and Mehri also indicated a significant positive correlation between social capital, social trust, social cohesion and the mental health of teachers [18]. In addition, results of Seyyedan and Abdolsamadi revealed a significant correlation between social capital and its indicators including social participation, social support network, social trust, personal trust, and generalized trust with mental health [19]. Moreover, Garousi and Shabestarinejad found a significant correlation between social trust, social participation, the size of social network and social capital and mental health of female-headed households in Kerman [20]. Norian Najafabad and Jahangir also showed a direct as well as significant relationship between 
the level of social trust and the level of mental health [21]. Furthermore, Landstedt et al, stated that involvement in social networks promotes mental health [22]. Results of Yiengprugsawan et al., indicated that high psychological health is associated with high social trust and social support [23].

Nevertheless, Shoja et al, found no significant relationship between mental health and trust [24] which might be due to the fact that that study was conducted among the elderly.

On the other hand, despite obtaining a positive relationship between mental health and social norm and social participation, this relationship was not statistically significantin the current invstigation is inconsistent with the findings of Share Pour et al [16], Lahsaeizadeh and Moradi [25] as well as Garousi and Shabestarinejad [20]. This inconsistency can be due to different study population as the mentioned studies were conducted among citizen in Tehran, immigrants to Kermanshah and household headed by women in Kerman.

Since the correlation coefficient between mental health and social capital in general was significant at the $1 \%$ level; therefore, it can be concluded that there is a relationship between mental health and social capital in general concerning 99\% confidence intervals (CIs).

Negahban et al, also found a relationship between mental health and social capital among the elderly in Tehran revealing that as the more the social capital is, the more the mental health is [26]. The study of Rajabi Gilan et al., also indicated a significant positive relationship between mental health and total social capital [14]. Furthermore, Lahsaeizadeh and Moradi found a positive and strong significant relationship between social capital and mental health of immigrants [25]. Zahedi Asl and Farokhi also revealed a significant relationship between social capital and quality of life and its 4 dimensions (physical, mental, social and environmental health) [15]. In addition, Nekonam et al, uncovered a direct significant relationship between within and out-group social capital and mental health [27]. The results of Haghighatian and Jafari also showed a positive and significant relationship between social capital and mental health [17]. Moreover, Colton et al, revealed that social capital explained much, but not all of single mothers' greater mental morbidity [28]. $\mathrm{Wu}$ et al, also found that social capital was as a mediator between migration status and mental health [29]. Furthermore, RiumalloHerl et al highlighted the potential role of social capital in preventing both depression and early cardiovascular disease [30].

This study had the following limitations:

- The lack of some household heads' cooperation and the low literacy rate of some respondents in completing the questionnaires; - The time-consuming process of completing the questionnaires due to being widely distributed as well as mountainous region of the studied area.

\section{Conclusion}

Since among the dimensions of social capital, social networks had the lowest mean score; therefore, it seems necessary to strengthen relationships with relatives, neighbors, and friends through educational media in order to improve social networks.

Furthermore, regarding that the mental health of the rural household heads had lower mean score in comparison with their physical health, some considerations such as providing free or low-cost counseling services by related authorities are recommended in order to improve the mental health.

With regard to the existing relationship between mental health and aspects of social trust, social networks and social cohesion, the increase of these dimensions of social capital requires further consideration to enhance the mental health.

\section{Acknowledgements}

The authors sincerely thank all the participants for their kind cooperation.

\section{Authors' contributions}

Study design: MN, ZSh

Data collection and analysis: ZSh 
Manuscript preparation: MN, ZSh

All authors have read and approved the final version

\section{Conflict of Interest}

"The authors declare that they have no competing interests."

\section{Funding}

The authors received no financial support for the research, authorship and/or publication of this article.

\section{Availability of data and materials}

The datasets used and/or analyzed during this study are available from the corresponding author on reasonable request.

\section{Reference}

1- Boojari S, Haghgoo H, Rostami R, Ghanbari S, Nematollahi S. Relationship between quality of life and cognitive function in school aged children with attention deficit and hyperactivity disorder. Journal of Research Health2016; 6(3): 345-54.

2- Afrakhteh H, Afkar A. Factors affecting villages' health level (Case study: Shaft District Villages). Journal of Research and Rural Planning2012; 1(1): 25-43.

3- Dehghani A. Evaluating and analyzing the health indices in rurals of nomadic settlement: (Case study: nomadic rurals of Fars and Isfahan Provinces). Journal of Research and Rural Planning2016; 4(4): 95-109.

4- Anabestani AA, Behzadi S. Assessment of rural health level and individual factors affecting it's in Mayobd County-Yazd. Journal of Spatial Planning2013; 3(1): $1-18$.

5- Koohi K, Soltani Bahram S. General health and multiple forms of capital. Bioethics Journal2014; 4(14): 137-65. 6- Sheikhi D, Rezvani MR, Mahdavi M. Measurement and analysis of health level in rural areas according to healthy village approach: a case study of Khondab county, Markazi Province. Journal of Village and Development2012; 15(2): 109-38.

7- Musalia J. Social capital and health in Kenya: A multilevel analysis. Soc Sci Med2016; 167: 11-19.

8- Mirsardoo T. Social capital and urban health (case of study: Garmsar City). Journal of Iranian Social Development Studies2014; 6(3): 87-95.

9- Gilbert KL, Quinn SC, Goodman RM, Butler J, Wallace J. A meta-analysis of social capital and health: A case for needed research. J Health Psychol2013; 18(11): 1385-99. 10- Fujisawa Y, Hamano T, Takegawa S. Social capital and perceived health in Japan: An ecological and multilevel analysis. Soc Sci Med2009; 69(4): 500-5.

11- Kim D, Kawachi I. U.S. state-level social capital and health-related quality of life: Multilevel evidence of main, mediating, and modifying effects. Ann Epidemiol2007; 17(4): 258-69.

12- Montazeri A, Goshtasebi A, Vahdaninia MS. Translation, Determination of reliability and validity of the Persian version of SF-36 questionnaire. Payesh2006; 5(1): 49-56.

13- Heidarnia MA, Ghaemian T, Abadi A, Fathian S, Montazeri A. Relationship between deprivation (Economic poverty) and health-related quality of life. Payesh2012; 11(4): 491-5.

14- Rjabi Gilan N, Ghaeemi SR, Reshadat S, Rajabi Gilan S. The relationship between social capital and health-related quality of life among teachers. Journal of Zanjan University of Medical Sciences and Health Services2013; 21(88): 95-107.

15-Zahedi Asl M, Farokhi J. Studying the relation of life quality and social capital. Quarterly Journal of Social Sciences2010; 1(49): 1-29.

16- Share Pour M, Riahi, MI, Arman F. The effect of social capital indicators on the mental health of citizens living in Tehran. Iranian Journal of Social Problems 2014; 5(1): 79-100.

17- Haghighatian M, Jafari E. The relationship of bonding social capital with mental health among slum dwellers. Social Welfare2013; 13(48): 131-49.

18- Hezar Jaribi J, Mehri A. Analysis of the relationship between social capital and mental and social health. Journal of Social Science 2013; 19(59): 42-90.

19- Seyyedan F, Abdolsamadi M. The relation of social capital with mental health in women and men. Social Welfare Quarterly2011; 11(42): 229-54.

20- Garousi S, Shabestarinejad SH. Social capital and mental health among household head women surveying the relationship in the City of Kerman. Journal of Iranian Social Studies 2011; 5(1): 99-123.

21- Norian Najafabadi M, Jahangir N. An analysis on the relationship between teachers' social trust and mental health. Journal of Historical Sociology2012; 3(2): 35-60. 22-LandstedtE,AlmquistYB, Eriksson M, Hammarström A. Disentangling the directions of associations between structural social capital and mental health: Longitudinal analyses of gender, civic engagement and depressive symptoms. Soc Sci Med2016; 163: 135-43.

23- Yiengprugsawan V, Khamman S, Seubsman S, Lim LLY, Sleigh AC. Social capital and health in a national cohort of 82,482 Open University adults in Thailand. $J$ Health Psychol2011; 16(4): 632-42.

24- Shoja M, Rimaz SH, Asadi Lari M, Bagheri Yazdi SA, Govhari MR. Mental health of older people and social capital. Payesh2013; 12(4): 345-53.

25- Lahsaeizadeh A, Moradi G. The relationship between 
social capital and mental health among immigrants. Social Welfare2007; 7(26): 161-80.

26- Negahban Z, Arab M, Tajvar M, Rahimi Foroshani A, Rashidyan A. To investigate the association between social capital and mental health in the ageing population of Tehran. Journal of Healthcare Management2015; 6(1): 79-88.

27- Nekonam MS, Ahamadi A, Asgari R. The effect of social capital (In-group and Out-group) on the students' mental health (Case study: students of Tabriz University). Sociological Studies of Youth (Jame Shenasi Motaleate Javanan)2015; 5(17): 163-84.
28- Colton T, Janzen B, Laverty W. Family structure, social capital, and mental health disparities among Canadian mothers. Pub Health2015; 129(6): 639-47.

29- $\mathrm{Wu} \mathrm{Q}, \mathrm{Lu}$ D, Kang M. Social capital and the mental health of children in rural China with different experiences of parental migration. Soc Sci Med2015; 132: $270-7$.

30- Riumallo-Herl CJ, Kawachi I, Avendano M. Social capital, mental health and biomarkers in Chile: assessing the effects of social capital in a middle-income country. Soc Sci Med2014; 105: 47-58.

Copyright $\odot 2016$ ASP Ins. This open-access article is published under the terms of the Creative Commons Attribution-NonCommercial 4.0 International License which permits Share (copy and redistribute the material in any medium or format) and Adapt (remix, transform, and build upon the material) under the Attribution-NonCommercial terms. 